\title{
Net-Patterned Fluorine-Doped Tin Oxide to Accelerate the Electrochromic and Photocatalytic Interface Reactions
}

\author{
Seock-Joon Jeong ${ }^{\dagger}$, Kue-Ho Kim ${ }^{\dagger}$ and Hyo-Jin Ahn * \\ A Department of Materials Science and Engineering, Seoul National University of Science and Technology, \\ Seoul 01811, Korea; 16100585@seoultech.ac.kr (S.-J.J.); kueho0131@seoultech.ac.kr (K.-H.K.) \\ * Correspondence: hjahn@seoultech.ac.kr; Tel.: +82-02-970-6622 \\ + S.-J. Jeong and K.-H. Kim contributed equally to this work.
}

Citation: Jeong, S.-J.; Kim, K.-H.; Ahn, H.-J. Net-Patterned

Fluorine-Doped Tin Oxide to

Accelerate the Electrochromic and Photocatalytic Interface Reactions. Catalysts 2021, 11, 249. https:// doi.org/10.3390/catal11020249

Academic Editor:

Nicolas Alonso-Vante

Received: 13 January 2021

Accepted: 10 February 2021

Published: 12 February 2021

Publisher's Note: MDPI stays neutral with regard to jurisdictional claims in published maps and institutional affiliations.

Copyright: (c) 2021 by the authors. Licensee MDPI, Basel, Switzerland. This article is an open access article distributed under the terms and conditions of the Creative Commons Attribution (CC BY) license (https:/ / creativecommons.org/licenses/by/ $4.0 /)$.

\begin{abstract}
In this study, the surface morphology of net-patterned fluorine-doped tin oxide (FTO) films was optimized with mesh sizes (60 mesh, 40 mesh, and 24 mesh) using the one-pot horizontal ultrasonic spray pyrolysis deposition (HUSPD) process. The 40M-FTO sample exhibited optimized electrical and optical properties due to the improved crystallinity and net-patterned surface morphology of FTO. The electrochromic (EC) electrodes fabricated with 40M-FTO showed superior EC performance, including transmittance modulation $(\Delta \mathrm{T}, 58.7 \%)$, switching speeds (4.1 s for coloration and $5.9 \mathrm{~s}$ for bleaching), and coloration efficiency $\left(\mathrm{CE}, 52.4 \mathrm{~cm}^{2} / \mathrm{C}\right)$. These optimum values were attributed to the combined effect of the enhanced electrical properties from the improved crystallinity of the $\mathrm{SnO}_{2}$ and the high transmittance with a large surface area stemming from the optimization of the net-patterned FTO surface morphology. Moreover, the improved reaction sites with large surface area and enhanced electrical conductivity can facilitate the photocatalytic reaction. Accordingly, we suggest our novel strategy for use in creating promising transparent conducting electrodes that can be fabricated with net-patterned FTO to realize enhanced electrochromic and photocatalytic interface reactions.
\end{abstract}

Keywords: transparent conducting oxide; electrical and optical properties; transition metal oxides; patterning; electrochromic performances

\section{Introduction}

With the advent of electrochromism, electrochromic devices (ECDs) have attracted much attention around the world due to their potential and wide use in areas such as cutting-edge displays, smart windows, and energy conservation devices [1-3]. ECDs can reversibly change their optical properties (transmittance, absorption, and reflectance) from electronic structure variations of electrochromic (EC) films. When an electric field is applied, EC films undergo electrochemical oxidation and a reduction reaction, accompanied by the transport of ions and electrons [4-7]. Typical ECDs are composed of the three main components of EC films (cathodic and anodic), an electrolyte, and transparent conducting oxide (TCO) layers, which can directly affect key performance outcomes of ECDs, such as the coloration efficiency (CE), switching speed, and transmittance modulation [8,9]. Among them, the TCO serves as an electron pathway, which connects the EC films with an external circuit and determines the overall transmittance of the ECD. Moreover, the TCO can be used for photocatalysis application due to its advantageous electronic properties and conductivity [10-13]. For example, Khalaf et al. demonstrated the photocatalytic behavior of Co-doped $\mathrm{TiO}_{2}$, and Jiamprasertboon et al. reported the optimized photocatalytic properties of $\mathrm{Cl}$-doped $\mathrm{ZnO}$ films with enhanced electrical and optical properties [14,15]. At this point, enhancing the electrical conductivity and transmittance of the TCO is suggested as one of the most effective strategies for improving the electrochromic and photocatalytic performances. Generally, transition metal oxide films, including tin-doped indium oxide (ITO), fluorine-doped tin oxide (FTO), and aluminum-doped zinc oxide (AZO), have been 
used as the TCO layer in ECDs [16-18]. Specifically, ITO has been widely used for broad optoelectronic applications (e.g., touch panels, electroluminescent devices, organic lightemitting diodes, and light sensors) as a typical TCO material due to its superior visible light transmittance $(>80 \%)$, low resistivity $\left(<10^{-3} \Omega \mathrm{cm}\right)$, and large band gap $(\sim 4.8 \mathrm{eV})[19,20]$. However, ITO has several drawbacks, including its high element cost, low mechanical strength, and low chemical stability, which considerably limit further applications. FTO was recently proposed as a substitute material due to its low cost and excellent mechanical and chemical durability. In order to achieve high transmittance while maintaining the electrical conductivity of FTO films, various methods have been suggested, including patterning, metal ion doping, and the use of layered structures [21,22]. For example, Lee et al. fabricated micro-patterned FTO films using a photolithography process and applied this method to ECDs with Prussian blue [23]. They reported enhanced electrochromic performance with patterned FTO, such as rapid switching speeds ( $\sim 30 \mathrm{~s})$ and large optical density levels $(>0.4)$. However, the conventional patterning process is associated with complex procedures, which require a patterned mask, UV light exposure, and the coating and stripping of a photoresist. Therefore, a progressive synthesis method for patterned FTO films with a simple process is needed to lower the manufacturing cost and enhance the electrical and optical properties.

In this study, we report a one-pot synthesis technique for net-patterned FTO films using the horizontal ultrasonic spray pyrolysis deposition (HUSPD) method with various types of stainless meshes. This simple synthesis method can effectively simplify the manufacturing procedure and decrease the time, allowing the realization of affordable net-patterned FTO films. Through an adjustment of the patterning size, the surface area and transmittance of the FTO films, factors that directly affect the EC performance were successfully optimized. To demonstrate this performance enhancement, the correlations of the morphological, structural, optical, and electrical properties and the EC performance outcomes were investigated in detail.

\section{Results and Discussion}

\subsection{Preparation and Morphological Properties}

Figure 1 shows an overall experimental illustration of the net-patterned FTO films created using the one-pot HUSPD process with a stainless mesh. Figure 1a displays an outline of the HUSPD system, which is composed of (1) a reaction furnace, (2) a gas flow controller, (3) a generator, and (4) a spraying bath with an ultrasonic atomizer [24]. The conventional USPD system uses a spraying head directly above the substrate with a vertically supplied precursor solution, which can cause nonuniform film structures. Distinctively, this HUSPD system uses horizontally supplied precursor droplets supplied by an ultrasonic atomizer and a gas flow for the pyrolysis process, which leads to the formation of uniformly coated film structures [25]. The atomized precursor droplets undergo the subsequent process of solvent evaporation, solute condensation, and thermal decomposition (pyrolysis) [26]. Moreover, HUSPD offers the advantage of allowing simple adjustments to experimental parameters, such as the frequency of the atomizer, the substrate rotating speed, and the gas flow rate, among others. Figure $1 \mathrm{~b}$ shows the manufacturing procedure used to synthesize the net-patterned FTO films. When the stainless mesh covers the glass substrate during the HUSPD process, the pyrolysis reaction occurs more actively on the uncovered area, which can readily generate the net pattern on the substrate. This one-pot synthesis of net-patterned FTO films can effectively decrease the time and cost of the patterning process compared to the photolithography method, which requires a patterned mask, UV exposure, and a photoresist. The net-patterned FTO films possess a large surface area with enhanced surface roughness and high transmittance because less of the area is coated. This ensures a significant EC performance improvement. To adjust the net-pattern size of the FTO glass, various types of meshes (60 mesh, 40 mesh, 24 mesh) were covered on the prepared glass substrate during the HUSPD process. For comparison, the HUSPD process was also 
conducted on a glass substrate without a cover mesh (samples are henceforth referred to as bare FTO, 60M-FTO, 40M-FTO, and 24M-FTO).

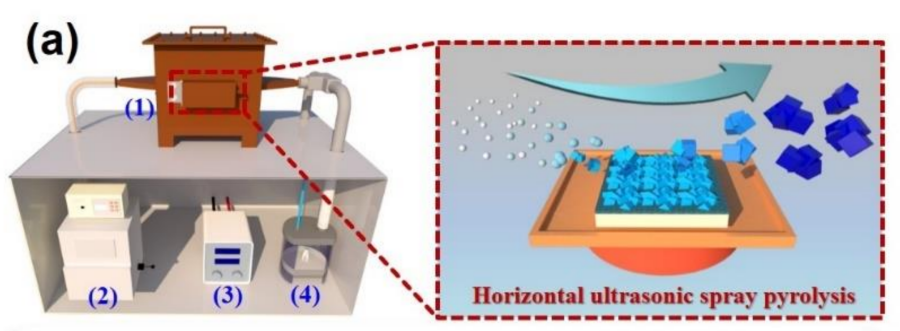

\section{(b)}

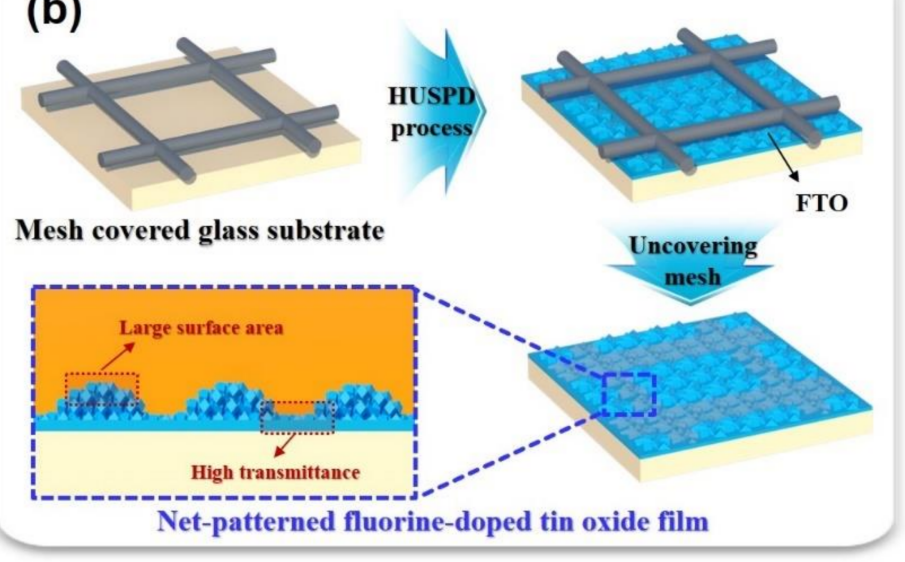

Figure 1. Schematic illustration of the procedure for the synthesis of net-patterned fluorine-doped tin oxide (FTO) film, (a) outline of the horizontal ultrasonic spray pyrolysis deposition (HUSPD) system, (b) manufacturing procedure including HUSPD process on the mesh covered substrate and mesh removal to synthesize the net-patterned FTO films.

Figure 2a,d correspondingly shows top-view optical microscope (OM) images of the bare FTO, 60M-FTO, 40M-FTO, and 24M-FTO samples prepared with different types of meshes. Figure 2a exhibits a smooth and uniform film structure over the entire area. In contrast, Figure $2 \mathrm{c}, \mathrm{d}$ shows a net-patterned morphology with various patterning sizes ( $250 \mathrm{um}$ for $60 \mathrm{M}-\mathrm{FTO}, \sim 500 \mathrm{um}$ for $40 \mathrm{M}-\mathrm{FTO}$, and $\sim 900 \mathrm{um}$ for $24 \mathrm{M}-\mathrm{FTO})$. This result is attributed to the different spacing sizes of the respective meshes, which takes a role as a pathway of sprayed precursor droplets during the HUSPD process.

Figure 3 shows the top-view and cross-view field-emission scanning electron microscope (FESEM) images of (a, e) bare FTO, (b, f) 60M-FTO, (c, g) 40M-FTO, and (d, h) 24M-FTO prepared by the HUSPD process, respectively. The average thickness of the FTO films was measured as $\sim 263.4 \mathrm{~nm}$ for bare FTO, $\sim 299.0$ for 60M-FTO, $\sim 346.5$ for $40 \mathrm{M}$ FTO, and $\sim 326.7 \mathrm{~nm}$ for $24 \mathrm{M}-\mathrm{FTO}$. Moreover, the average crystal size was measured as $\sim 144.2 \mathrm{~nm}$ for bare FTO, $184.1 \mathrm{~nm}$ for $60 \mathrm{M}-\mathrm{FTO}, \sim 204.5 \mathrm{~nm}$ for $40 \mathrm{M}-\mathrm{FTO}$, and $\sim 226.3 \mathrm{~nm}$ for 24M-FTO. The increased film thickness and crystal size of 40M-FTO can be attributed to the carrier concentration and crystallinity enhancement [7,27].

\subsection{Structral and Chemical Properties}

To investigate the surface properties further, a confocal laser scanning microscope (CLSM) analysis was conducted, as this method can profile a 3D surface structure and evaluate the surface area and roughness of films (see Figure 4a). The average depth and height values were increased from $0.115 \mathrm{um}$ for the bare FTO sample to $0.205 \mathrm{um}$ for the 60M-FTO sample and to $0.382 \mathrm{um}$ for the $40 \mathrm{M}-\mathrm{FTO}$ sample. This result is caused by the net-patterning and increment of the spacing size according to the mesh type. While 60MFTO showed the largest number of patterns, the spacing area of the 60 mesh is not large enough to accommodate a sufficient amount of precursor droplets. Moreover, 24M-FTO 
shows lower average depth and height values than 40M-FTO in spite of the large spacing area, stemming from the deficient number of patterns in this case. The surface area values of all samples also exhibit the same tendency, with average depth and height values of $187.2 \times 10^{3} \mathrm{um}^{2}$ for the bare FTO sample, $198.5 \times 10^{3} \mathrm{um}^{2}$ for $60 \mathrm{M}$-FTO, $221.7 \times 10^{3} \mathrm{um}^{2}$ for $40 \mathrm{M}-\mathrm{FTO}$, and $212.6 \times 10^{3} \mathrm{um}^{2}$ for $24 \mathrm{M}-\mathrm{FTO}$. The surface area and roughness were optimized in the 40M-FTO case, which can provide an additional interface between EC films and the TCO layer and facilitate the electrochemical reaction of ECDs [28,29].

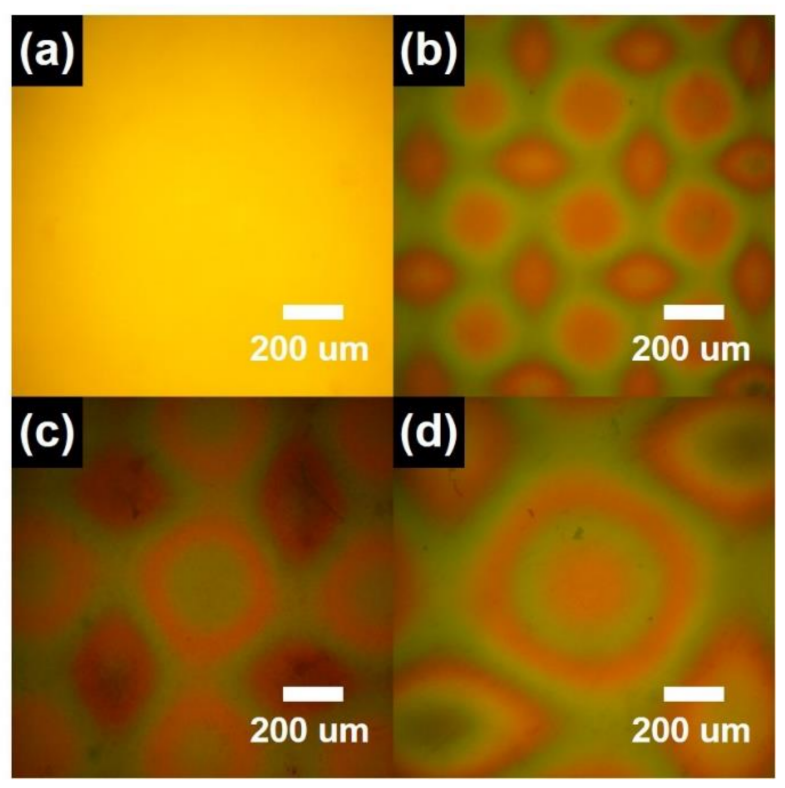

Figure 2. (a-d) Optical microscope (OM) images of the bare FTO, 60M-FTO, 40M-FTO, and 24M-FTO samples, respectively.

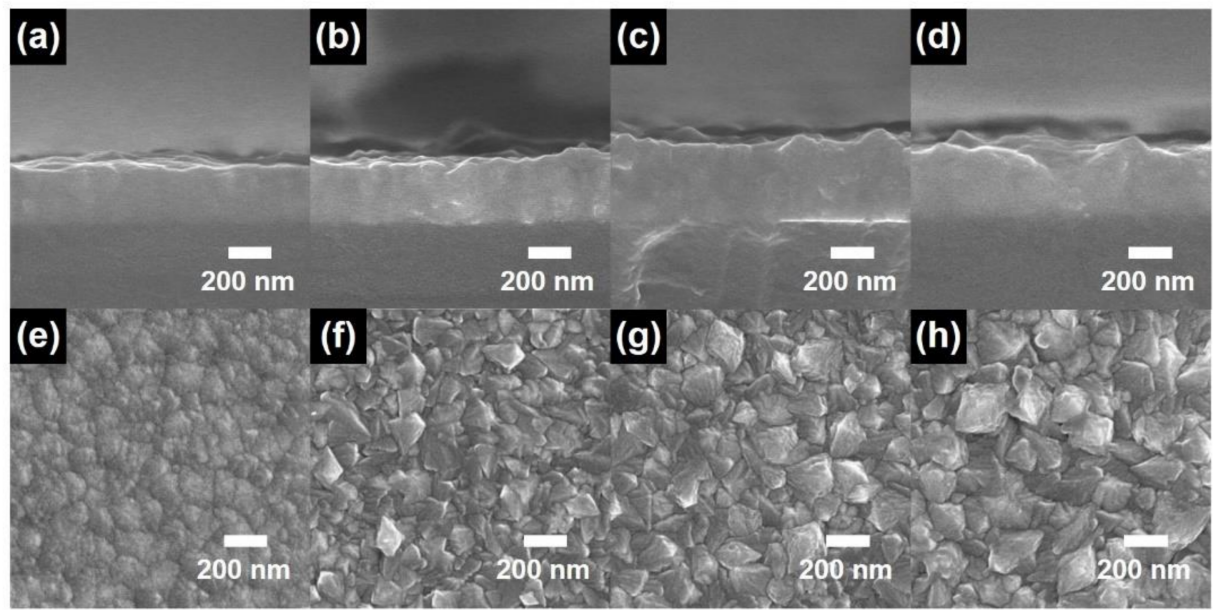

Figure 3. Top-view and cross-view FESEM images of (a,e) bare FTO, (b,f) 60M-FTO, (c,g) 40M-FTO, and (d,h) 24M-FTO, respectively.

To investigate the crystal structure, XRD measurements were taken of the bare FTO, 60M-FTO, 40M-FTO, and 24M-FTO samples (see Figure 4b). All FTO films fabricated by the HUSPD process showed characteristic diffraction peaks at $26.61^{\circ}, 33.89^{\circ}, 38.10^{\circ}$, and $51.78^{\circ}$, corresponding to the (110), (101), (200), and (211) planes of the $\mathrm{SnO}_{2}$ phase (JCPDS (Joint Committee on Powder Diffraction Standards) card No. \#88-0287) [30]. In the bare FTO case, the lowest crystallinity was detected due to the low pyrolysis temperature of $350{ }^{\circ} \mathrm{C}$ and relatively short deposition time compared to the net-patterned FTO films [31]. This enhanced crystallinity of net-patterned FTO films can contribute to important electrical 
properties, including the carrier concentration and mobility. Specifically, 40M-FTO showed the highest $(200) /(110)$ plane intensity ratio of 1.25 compared to the value of 0.52 for $60 \mathrm{M}-\mathrm{FTO}$ and 0.80 for $24 \mathrm{M}-\mathrm{FTO}$, which is known to be a preferred structure for electron transfer $[32,33]$. The improvement of the electrical properties of the TCO layer will strongly affect the switching speeds of ECDs. Therefore, the formation of net-patterned FTO films with the (200) preferred orientations can be successfully achieved using the HUSPD process, which can provide efficient electron transport within the TCO layer.
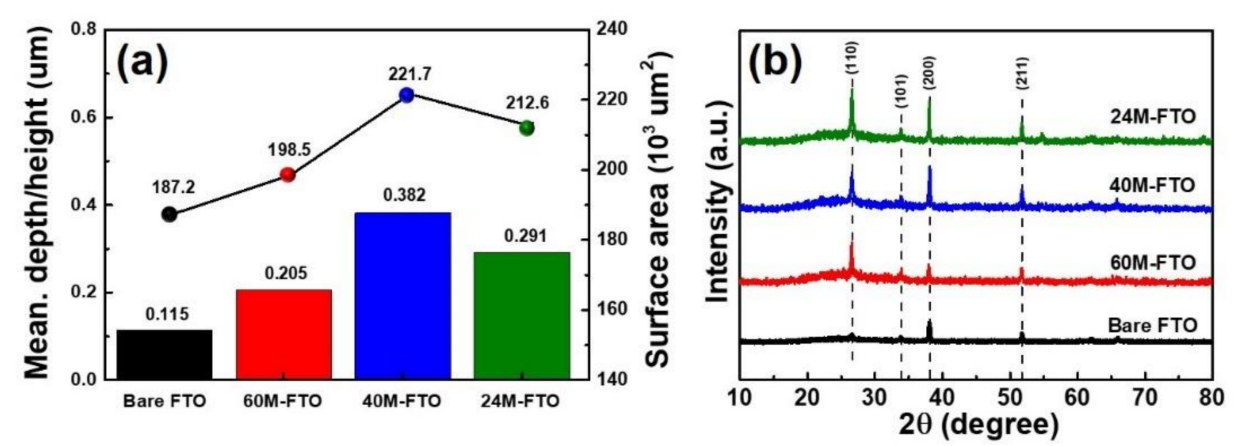

Figure 4. (a) Measured average depth and height values and surface area of bare FTO, 60M-FTO, 40MFTO, and 24M-FTO samples and (b) XRD curves of bare FTO, 60M-FTO, 40M-FTO, and 24M-FTO samples, implying crystallinity enhancement from bare FTO to $24 \mathrm{M}-\mathrm{FTO}$.

Figure 5 shows the electrical and optical properties with the calculated figure of merit for all of the samples. The electrical properties (resistivity, carrier concentration, and Hall mobility) of the samples were examined using a Hall-effect measurement system (see Figure 5a). Interestingly, the carrier concentration and Hall mobility of the net-patterned FTO films were enhanced compared to those of the bare FTO films. As summarized in Table 1, the carrier concentration was improved from $7.82 \times 10^{20} \mathrm{~cm}^{-3}$ for the bare FTO to $1.02 \times 10^{21} \mathrm{~cm}^{-3}$ for $60 \mathrm{M}$-FTO and to $1.21 \times 10^{21} \mathrm{~cm}^{-3}$ for $40 \mathrm{M}$-FTO. The Hall mobility was also increased from $12.8 \mathrm{~cm}^{2} /(\mathrm{V} \cdot \mathrm{s})$ for the bare FTO to $19.1 \mathrm{~cm}^{2} /(\mathrm{V} \cdot \mathrm{s})$ for $60 \mathrm{M}$-FTO and to $22.8 \mathrm{~cm}^{2} /(\mathrm{V} \cdot \mathrm{s})$ for $40 \mathrm{M}-\mathrm{FTO}$. These results are ascribed to the enhanced crystallinity and FTO film thickness [34]. However, for 24M-FTO, decreased carrier concentration $\left(1.14 \times 10^{21} \mathrm{~cm}^{-3}\right)$ and Hall mobility $\left(21.8 \mathrm{~cm}^{2} /(\mathrm{V} \cdot \mathrm{s})\right)$ outcomes were observed due to the reduced value of the $(200) /(110)$ plane ratio, which offers advantages in terms of the electrical properties. Therefore, the 40M-FTO sample exhibited optimum electrical properties, including the lowest resistivity of $4.27 \times 10^{-4} \Omega \cdot \mathrm{cm}$. Figure $5 \mathrm{~b}$ displays the optical transmittance curve of the bare FTO, 60M-FTO, 40M-FTO, and 24M-FTO samples measured in the wavelength range of $300 \mathrm{~nm}$ to $800 \mathrm{~nm}$. The bare FTO showed the lowest average transmittance of $80.3 \%$ in the visible range $(400 \sim 800 \mathrm{~nm})$, caused by considerable light scattering due to the dense FTO films with low crystallinity [35]. On the other hand, the net-patterned FTO films showed superior average transmittance outcomes of $89.8 \%, 88.9 \%$, and $86.2 \%$ for $60 \mathrm{M}-\mathrm{FTO}, 40 \mathrm{M}-\mathrm{FTO}$, and $24 \mathrm{M}-\mathrm{FTO}$, as high transmittance is one of the representative achievements of this patterning method (light penetration through the patterns). The figure of merit $\left(\varphi=T^{10} / R_{\mathrm{sh}}\right)$ was calculated from obtained transmittance $(T)$ and sheet resistance values $\left(R_{\text {sh }}\right)$, and $40 \mathrm{M}$-FTO showed the highest value of $3.84 \times 10^{-2} \Omega^{-1}$, as expected [36]. Therefore, the electrical and optical properties were optimized in the 40M-FTO case. This combination can therefore represent key factors for better EC performances. 

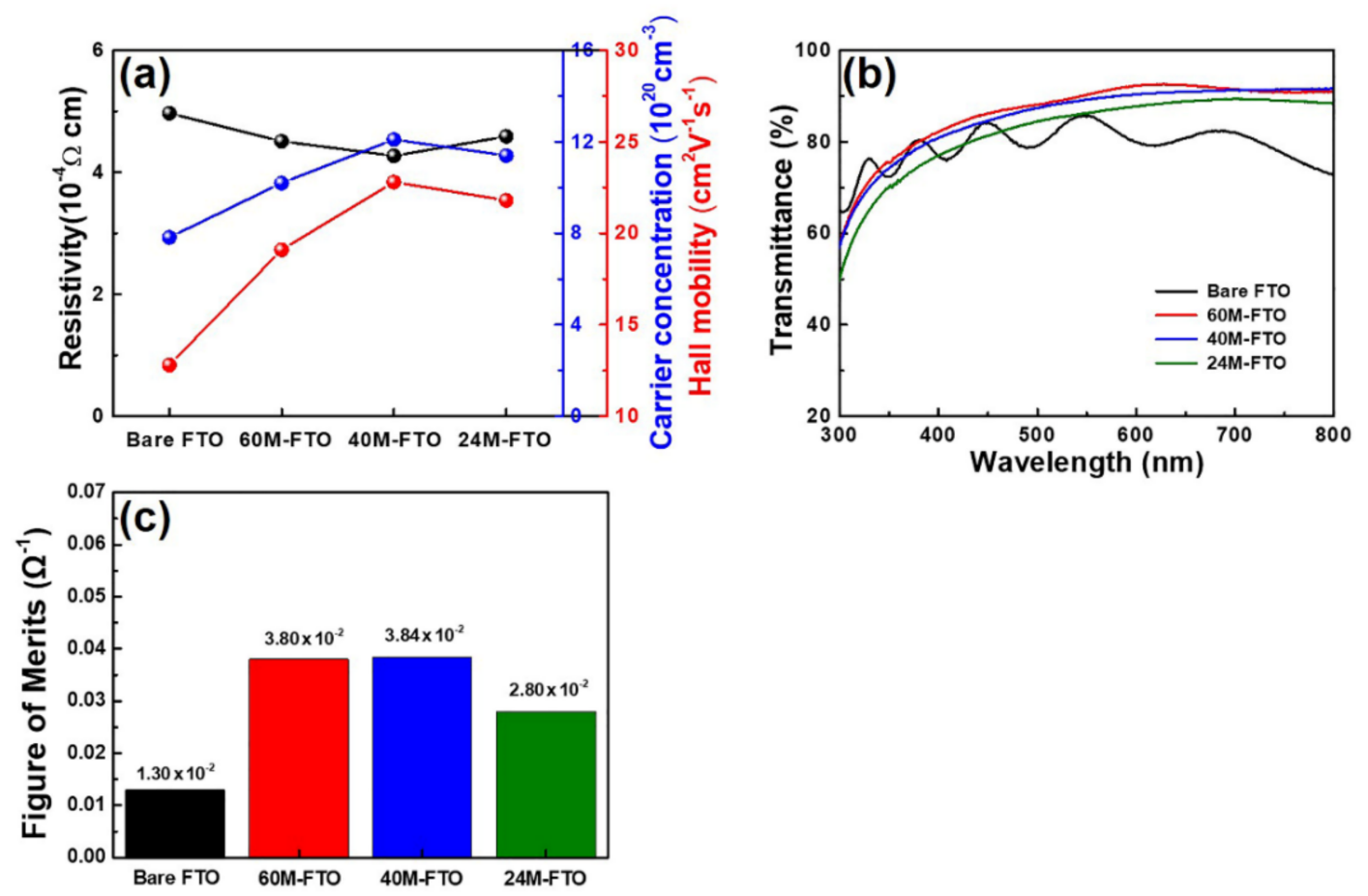

Figure 5. Electrical and optical properties of bare FTO, 60M-FTO, 40M-FTO, and 24M-FTO, respectively. (a) Electrical properties with carrier concentration, Hall mobility, and resistivity, (b) optical transmittance in the wavelength range of $300 \sim 800 \mathrm{~nm}$, and (c) FOM (Figure of merits) values.

Table 1. Summarized electrical and optical data of bare FTO, 60M-FTO, 40M-FTO and 24M-FTO samples.

\begin{tabular}{ccccc}
\hline Samples & Bare FTO & 60M-FTO & 40M-FTO & 24M-FTO \\
\hline Carrier concentration $\left(\mathrm{cm}^{-3}\right)$ & $7.82 \times 10^{20}$ & $1.02 \times 10^{21}$ & $1.21 \times 10^{21}$ & $1.14 \times 10^{21}$ \\
Mobility $\left(\mathrm{cm}^{2} / \mathrm{V} \cdot \mathrm{S}\right)$ & $1.28 \times 10$ & $1.91 \times 10$ & $2.28 \times 10$ & $2.18 \times 10$ \\
Resistivity $(\Omega \cdot \mathrm{cm})$ & $4.97 \times 10^{-4}$ & $4.51 \times 10^{-4}$ & $4.27 \times 10^{-4}$ & $4.59 \times 10^{-4}$ \\
Sheet resistance $(\Omega / \square)$ & $8.39 \pm 0.17$ & $8.98 \pm 0.13$ & $8.03 \pm 0.21$ & $8.11 \pm 0.24$ \\
Transmittance $(\%)$ & 80.3 & 89.8 & 88.9 & 86.2 \\
Figure of Merit $\left(\Omega^{-1}\right)$ & $1.30 \times 10^{-2}$ & $3.80 \times 10^{-2}$ & $3.84 \times 10^{-2}$ & $2.80 \times 10^{-2}$ \\
\hline
\end{tabular}

\subsection{Electrochemical and Electrochromic Performance}

To demonstrate the enhancing effect of TCO layers on the ECDs, all fabricated FTO films were coated with $\mathrm{WO}_{3}$ film and annealed at $300{ }^{\circ} \mathrm{C}$ to form a FTO- $\mathrm{WO}_{3}$ EC electrode. Figure 6 shows the $\mathrm{CV}$ (Cyclic voltammetry) curves of all of the EC electrodes fabricated with bare FTO, 60M-FTO, 40M-FTO, and 24M-FTO. During the cycling process, all of the electrodes exhibited a single pair of reduction-oxidation (redox) curves with respective anodic and cathodic peaks. The redox reaction indicates the intercalation and deintercalation of $\mathrm{Li}$ ion and electron transfers to the $\mathrm{WO}_{3}$ films, accompanied by a reversible color change from a bleached state (transparent) to a colored state (deep blue). The current density levels of the both the anodic and cathodic peaks were gradually increased from the bare FTO to the 40M-FTO sample. This result implies the enhancement of electrochemical activity due to the additional interface area between the EC film and the TCO layer, causing an increased number of ions and electrons participating in the redox reaction [37]. However, the EC electrode with 24M-FTO showed a slight reduction in the peak current density due to the decreased number of patterns, as expected from the aforementioned surface area and mean depth/height data in the CLSM results. 


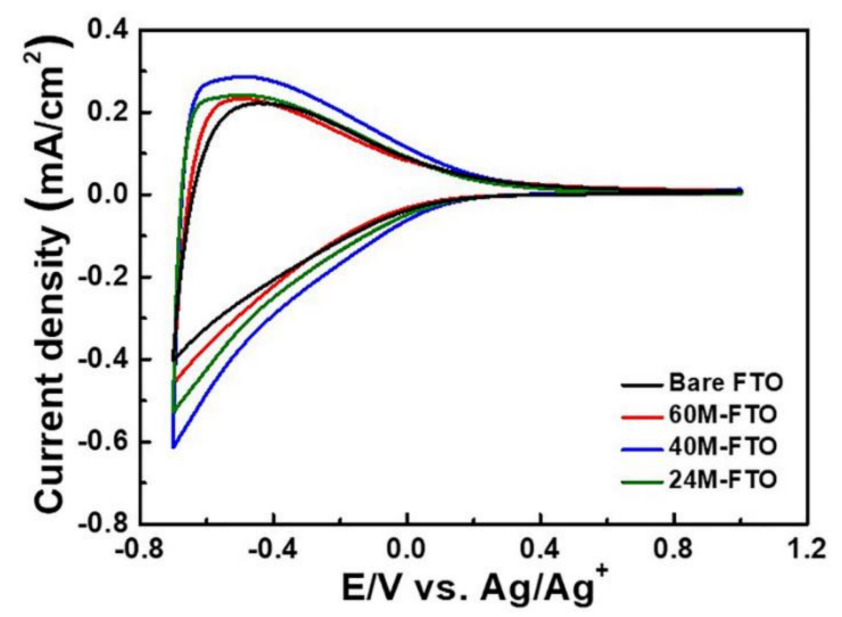

Figure 6. CV (cyclic voltammetry) curves of all samples measured between -0.7 and $1.0 \mathrm{~V}$ at the scan rate of $20 \mathrm{mV} / \mathrm{s}$ using three-electrode system.

Figure 7a presents the in-situ optical transmittance of the fabricated $\mathrm{FTO}-\mathrm{WO}_{3} \mathrm{EC}$ electrodes at a wavelength of $633 \mathrm{~nm}$ and with the potential repeatedly applied at $-0.7 \mathrm{~V}$ (colored state) and $1.0 \mathrm{~V}$ (colored state) to all of the electrodes. As summarized in Table 2, the transmittance modulation $(\Delta \mathrm{T}$, transmittance gap between the colored and bleached states), switching speed (response time to attain $90 \%$ of the $\Delta \mathrm{T}$ ), and coloration efficiency (CE) of all electrodes were measured. The 40M-FTO sample exhibited the highest $\Delta \mathrm{T}$ of $58.7 \%$, which is $9.9 \%$ higher than that in the bare FTO case. This result is attributed to the increment of the transmittance in the bleached state caused by the optimized netpatterned morphology of the FTO films. The reduced transmittance in the colored state was caused by the facilitated electrochemical activity through the large interfacial area between the EC film and TCO layer. Moreover, shortened switching speeds were noted in the $40 \mathrm{M}-\mathrm{FTO}$ case $(4.1 \mathrm{~s}$ for the coloration speed and $5.9 \mathrm{~s}$ for the bleaching speed) compared to the bare FTO case (11.0 s for the coloration speed and $11.0 \mathrm{~s}$ for the bleaching speed) and the other net-patterned FTO films. The fast switching speed of 40M-FTO is associated with the optimized electrical properties, including the carrier concentration and Hall mobility, boosting the electron and Li ion transport within the ECDs during the electrochemical reaction. Figure $7 \mathrm{~b}$ shows the calculated $\mathrm{CE}$ values of all electrodes, signifying comprehensive EC performance [38,39].
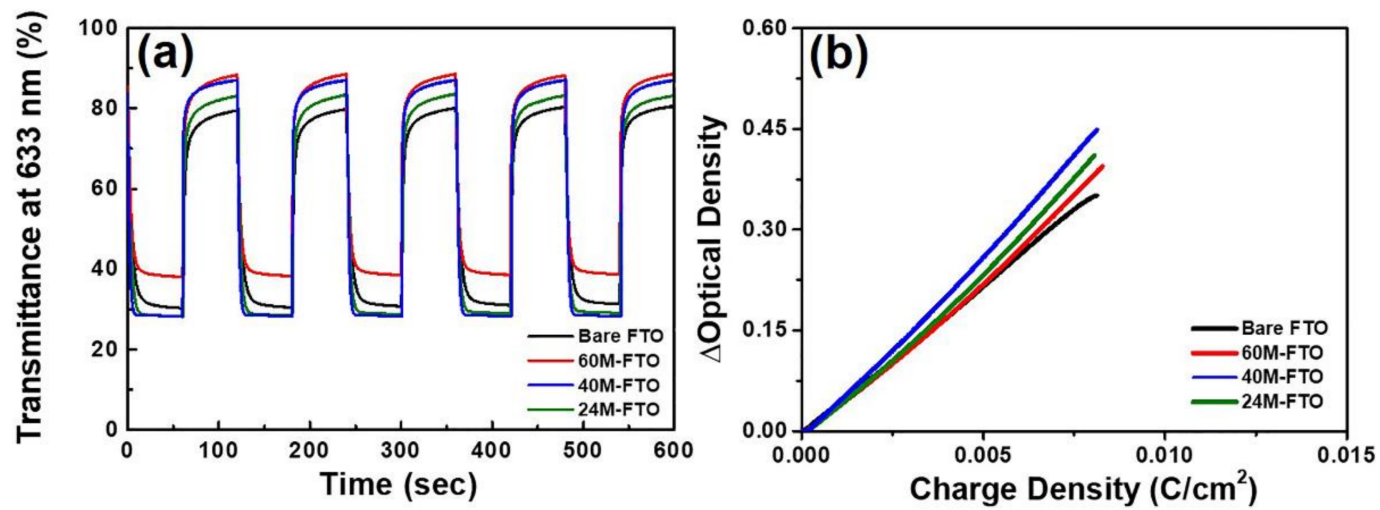

Figure 7. (a) In situ optical transmittance curves investigated with the repetitive potential at $-0.7 \mathrm{~V}$ for the colored state and $1.0 \mathrm{~V}$ for the bleached state and $(\mathbf{b})$ optical density variation by the charge density insertion. 
Table 2. Summarized electrochromic performance of all the $\mathrm{FTO}-\mathrm{WO}_{3}$ electrodes.

\begin{tabular}{ccccccc}
\hline Samples & $\begin{array}{c}\mathbf{T}_{\text {bleached }} \\
\mathbf{( \% )}\end{array}$ & $\begin{array}{c}\mathbf{T}_{\text {colored }} \\
\mathbf{( \% )}\end{array}$ & $\begin{array}{c}\text { Modulation } \\
\mathbf{( \% )}\end{array}$ & $\begin{array}{c}\text { Switching Speed } \\
\text { (Colored) }\end{array}$ & $\begin{array}{c}\text { Switching Speed } \\
\text { (Bleached) }\end{array}$ & $\begin{array}{c}\text { Coloration } \\
\left.\text { Efficiency }_{(\mathbf{c m}} \mathbf{2} / \mathbf{C}\right)\end{array}$ \\
\hline Bare FTO & 80.1 & 31.3 & 48.8 & 11.0 & 11.0 & 38.2 \\
60M-FTO & 88.3 & 38.3 & 50.0 & 7.5 & 10.3 & 4.9 \\
40M-FTO & 87.0 & 28.3 & 58.7 & 4.1 & 9.5 & 52.6 \\
24M-FTO & 83.3 & 31.9 & 54.5 & 6.2 & 9.5 & 47.3 \\
\hline
\end{tabular}

The CE value is defined as the optical density (OD) according to the charge densities $(Q / A)$. It is calculated using Equations (1) and (2). The $C E$ values were $38.2 \mathrm{~cm}^{2} / \mathrm{C}$ for the bare FTO, $42.6 \mathrm{~cm}^{2} / \mathrm{C}$ for the $60 \mathrm{M}-\mathrm{FTO}$ sample, $52.4 \mathrm{~cm}^{2} / \mathrm{C}$ for the $40 \mathrm{M}-\mathrm{FTO}$ sample, and $47.3 \mathrm{~cm}^{2} / \mathrm{C}$ for the $24 \mathrm{M}-\mathrm{FTO}$ sample, indicating that $40 \mathrm{M}$-FTO exhibited optimized EC performance. This outcome is attributed to the large value of $\Delta \mathrm{T}$ from the net-patterning process and the enhanced electrochemical activity from the additional surface area of the FTO films.

$$
\begin{aligned}
& \mathrm{CE}=\Delta \mathrm{OD} /(\mathrm{Q} / A) \\
& \Delta \mathrm{OD}=\log \left(T_{\mathrm{b}} / T_{\mathrm{c}}\right)
\end{aligned}
$$

Thus, superior EC performance was achieved at the electrodes with the 40M-FTO TCO layer, mainly due to the optimized net-patterning process using the one-pot HUSPD method. Firstly, the net-patterned FTO morphology effectively enhanced the surface area and transmittance of the TCO layer, which can affect the $\triangle T$ and CE values. Secondly, optimized electrical properties, in this case the carrier concentration and Hall mobility, were realized due to the improved FTO crystallinity. Therefore, using the HUSPD process with various types of stainless meshes can be suggested as a simple and effective method for the patterning of TCO materials onto substrates.

\section{Materials and Methods}

\subsection{Experimental Details}

The net-patterned FTO films were successfully fabricated on glass substrates (Corning, Eagle XGTM) using the one-pot HUSPD (Ceon, TV 500, Hwaseong, Korea) process with a stainless mesh (Goryeo Ltd., SUS 304, Seoul, Korea). First, the glass substrates were cleaned with acetone $\left(\mathrm{CH}_{3} \mathrm{COCH}_{3}\right.$, Aldrich) and ethanol $\left(\mathrm{CH}_{3} \mathrm{CH}_{2} \mathrm{OH}\right.$, DUKSAN) using ultrasonication for $25 \mathrm{~min}$ and then washed with de-ionized (DI) water. Subsequently, to prepare the precursor solution for the HUSPD process, $0.68 \mathrm{M}$ tin chloride pentahydrate $\left(\mathrm{SnCl}_{4} \cdot 5 \mathrm{H}_{2} \mathrm{O}\right.$, SAMCHUN) and $1.2 \mathrm{M}$ ammonium fluoride $\left(\mathrm{NH}_{4} \mathrm{~F}\right.$, JUNSEI) were dissolved into DI water with $5 \mathrm{vol} \%$ ethanol. After stirring for $3 \mathrm{~h}$, the solution turned transparent, and this precursor solution was poured into an ultrasonic atomizer $(1.6 \mathrm{MHz})$. The temperature of the pyrolysis chamber, the carrier gas (air) flow rate, and the rotation speed were correspondingly fixed at $350{ }^{\circ} \mathrm{C}, 15 \mathrm{~L} / \mathrm{min}$, and $5 \mathrm{rpm}$ for the HUSPD process. Due to the existence of stainless meshes and the difference of spacing sizes of them, the loading amount of sprayed precursor droplets onto the substrate was varied for each sample. Thus, for comparison, we adjusted the deposition time $(15,35,30$, and $25 \mathrm{~min}$ for the bare FTO, 60M-FTO, 40M-FTO, and 24M-FTO) to collect FTO samples with similar sheet resistance $(\sim 8 \Omega / \square)$.

\subsection{Characterization}

\subsubsection{Structures and Morphologies}

The surface morphology and roughness were investigated using optical microscopy (OM, Microscopes INC., S39B), field-emission scanning electron microscopy (FESEM, Hitachi S-4800) and a 3D surface confocal laser scanning microscope (CLSM, Carl Zeiss, LSM $800 \mathrm{MAT}$ ). The crystal structures were examined using X-ray diffraction (XRD, Rigaku $\mathrm{D} / \mathrm{Max}-2500)$ with $\mathrm{Cu} \mathrm{K}_{\alpha}$ radiation. The electrical and optical properties were ascer- 
tained using a Hall-effect measurement method (Ecopia, HMS-3000) and ultraviolet-visible spectroscopy (UV-vis, Perkin-Elmer, Lambda-35), respectively.

\subsubsection{Electrochemical Measurements}

To identify the electrochemical characteristics and EC performance outcomes, a potentiostat/galvanostat system (PGSTAT302N, FRA32M, Metrohm Autolab B.V., The Netherlands) was used. These measurements were conducted via a three-electrode cell with $\mathrm{Ag}$ wire (reference electrode), $\mathrm{Pt}$ wire (counter electrode), and $1 \mathrm{M} \mathrm{LiClO}_{4}$ dissolved in anhydrous propylene carbonate $\left(\mathrm{C}_{4} \mathrm{H}_{6} \mathrm{O}_{3}\right.$, Aldrich) (electrolyte). Cyclic voltammetry assessments were conducted from -0.7 to $1.0 \mathrm{~V}$ at a scan rate of $20 \mathrm{mV} / \mathrm{s}$. Moreover, the in-situ transmittance variation during the coloration and beaching process was observed using UV-vis specifically to demonstrate the EC performance capabilities.

\section{Conclusions}

In summary, the surface morphologies of net-patterned FTO films were optimized with the various types of meshes (60 mesh, 40 mesh, and 24 mesh) using the one-pot HUSPD process. We confirmed that the FTO patterning procedure with the proposed method can provide a performance enhancement of ECDs. Here, the 40M-FTO sample exhibited excellent EC performance outcomes, such as a large $\Delta \mathrm{T}$ value of $58.7 \%$, fast switching speeds ( $4.1 \mathrm{~s}$ for the coloration speed and $5.9 \mathrm{~s}$ for the bleaching speed), and a high $C E$ value of $52.4 \mathrm{~cm}^{2} / \mathrm{C}$. These results are mainly due to the (1) superior electrical properties of the dominant (200) plane crystal orientation, and (2) the high transmittance with the optimized net-patterned FTO morphology. These results are highly prospected to lead the current research trend of TCO materials in photocatalysis and ECD applications with excellent optical and electrical properties. In conclusion, optimized net-patterned FTO films using the one-pot HUSPD system can serve as an excellent reference for researchers who focus on TCO materials for photocatalysis and ECD applications.

Author Contributions: Conceptualization, S.-J.J., K.-H.K. and H.-J.A.; methodology, S.-J.J., K.-H.K.; validation, S.-J.J., K.-H.K. and H.-J.A.; formal analysis, S.-J.J., K.-H.K. and H.-J.A.; investigation, S.-J.J., K.-H.K.; resources, H.-J.A.; data curation, S.-J.J.; writing — original draft preparation, K.-H.K. and H.-J.A.; writing—review and editing, S.-J.J., K.-H.K. and H.-J.A.; visualization, S.-J.J., K.-H.K.; supervision, H.-J.A.; project administration, H.-J.A.; funding acquisition, H.-J.A. All authors have read and agreed to the published version of the manuscript.

Funding: This study was supported by the Research Program funded by SeoulTech (Seoul National University of Science and Technology).

Conflicts of Interest: The authors declare no conflict of interest.

\section{References}

1. Kim, J.-W.; Myoung, J.-M. Flexible and Transparent Electrochromic Displays with Simultaneously Implementable Subpixelated Ion Gel-Based Viologens by Multiple Patterning. Adv. Funct. Mater. 2019, 29, 1808911. [CrossRef]

2. Wang, Z.; Wang, X.; Cong, S.; Chen, J.; Sun, H.; Chen, Z.; Song, G.; Geng, F.; Chen, Q.; Zhao, Z. Towards full-colour tunability of inorganic electrochromic devices using ultracompact fabry-perot nanocavities. Nat. Commun. 2020, 11, 302. [CrossRef]

3. Granqvist, C.G. Transparent Conductive Electrodes for Electrochromic Devices: A Review. Appl. Phys. A 1993, 57, 19-24. [CrossRef]

4. Jo, M.-H.; Koo, B.-R.; Ahn, H.-J. Accelerating F-doping in transparent conducting F-doped $\mathrm{SnO}_{2}$ films for electrochromic energy storage devices. Ceram. Int. 2020, 46, 25066-25072. [CrossRef]

5. Yu, F.; Liu, W.; Ke, S.-W.; Kurmoo, M.; Zuo, J.-L.; Zhang, Q. Electrochromic two-dimensional covalent organic framework with a reversible dark-to-transparent switch. Nat. Commun. 2020, 11, 5534. [CrossRef]

6. Chan, J.Y.T.; Ang, S.Y.; Ye, E.Y.; Sullivan, M.; Zhang, J.; Lin, M. Heterogeneous photo-Fenton reaction on hematite $\left(a-\mathrm{Fe}_{2} \mathrm{O}_{3}\right)\{104\}$, $\{113\}$ and $\{001\}$ surface facets. Phys. Chem. Chem. Phys. 2015, 17, 25333-25341. [CrossRef]

7. Ye, E.; Zhang, S.-Y.; Lim, S.H.; Liu, S.; Han, M.-Y. Morphological tuning, self-assembly and optical properties of indium oxide nanocrystals. Phys. Chem. Chem. Phys. 2010, 12, 11923-11929. [CrossRef] [PubMed]

8. Wen, R.-T.; Granqvist, C.G.; Niklasson, G.A. Eliminating degradation and uncovering ion-trapping dynamics in electrochromic $\mathrm{WO}_{3}$ thin films. Nat. Mater. 2015, 14, 996-1001. [CrossRef] 
9. Kim, K.-H.; Koo, B.-R.; Ahn, H.-J. Sheet resistance dependence of fluorine-doped tin oxide films for high-performance electrochromic devices. Ceram. Int. 2018, 44, 9408-9413. [CrossRef]

10. Sathasivam, S.; Bhachu, D.S.; Lu, Y.; Chadwich, N.; Althabaiti, S.A.; Alyoubi, A.O.; Basahel, S.N.; Carmalt, C.J.; Parkin, I.P. Tungsten Doped $\mathrm{TiO}_{2}$ with Enhanced Photocatalytic and Optoelectrical Properties via Aerosol Assisted Chemical Vapor Deposition. Sci. Rep. 2015, 5, 10952. [CrossRef] [PubMed]

11. Zhang, X.; Chen, Y.; Zhang, S.; Qiu, C. High photocatalytic performance of high concentration Al-doped ZnO nanoparticles. Sep. Purif. Technol. 2017, 172, 236-241. [CrossRef]

12. Dinh, N.N.; Quyen, N.M.; Chung, D.N.; Zikova, M.; Truong, V.-V. Highly-efficient electrochromic performance of nanostructured $\mathrm{TiO}_{2}$ films made by doctor blade technique. Sol. Energy Mater. Sol. Cells 2011, 95, 618-623. [CrossRef]

13. Wang, B.; Man, W.; Yu, H.; Li, Y.; Zheng, F. Fabrication of Mo-Doped WO3 Nanorod Arrays on FTO Substrate with Enhanced Electrochromic Properties. Materials 2018, 11, 1627. [CrossRef] [PubMed]

14. Jiamprasertboon, A.; Dixon, S.C.; Sathasivam, S.; Powell, M.J.; Lu, Y.; Siritanon, T.; Carmalt, C.J. Low-Cost One-Step Fabrication of Highly Conductive ZnO:Cl Transparent Thin Films with Tunable Photocatalytic Properties via Aerosol-Assisted Chemical Vapor Deposition. ACS Appl. Electron. Mater. 2019, 1, 1408-1417. [CrossRef] [PubMed]

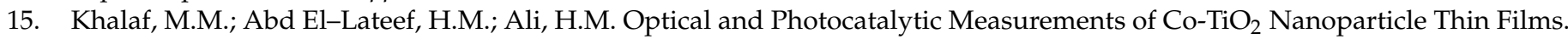
Plasmonics 2018, 13, 1795-1802. [CrossRef]

16. Yang, S.-H.; Yang, J.-H. Enhancement on electrochromic properties of $\mathrm{WO}_{3}$-based electrode prepared with hierarchical $\mathrm{ZnO}$ nanobricks. Vacuum 2020, 179, 109460. [CrossRef]

17. Zhao, Q.; Fang, Y.; Qiao, K.; Wei, W.; Yao, Y.; Gao, Y. of $\mathrm{WO}_{3} / \mathrm{ITO}$ nanocomposite electrochromic smart windows. Sol. Energy Mater. Sol. Cells 2019, 194, 95-102. [CrossRef]

18. Wang, M.; Xing, X.; Perepichka, I.F.; Shi, Y.; Zhou, D.; Wu, P.; Meng, H. Electrochromic Smart Windows Can Achieve an Absolute Private State through Thermochromically Engineered Electrolyte. Adv. Funct. Mater. 2019, 9, 1900433. [CrossRef]

19. Kim, H.; Kushto, G.P.; Auyeung, R.C.Y.; Piqué, A. Optimization of F-doped $\mathrm{SnO}_{2}$ electrodes for organic photovoltaic devices. Appl Phys. A Mater. Sci. Process. 2008, 93, 521-526. [CrossRef]

20. Kim, K.-H.; Koo, B.-R.; Ahn, H.-J. Effects of Sb-doped $\mathrm{SnO}_{2}-\mathrm{WO}_{3}$ nanocomposite on electrochromic performance. Ceram. Int 2019, 45, 15990-15995. [CrossRef]

21. Jo, M.-H.; Koo, B.-R.; Ahn, H.-J. Fe co-doping effect on fluorine-doped tin oxide transparent conducting films accelerating electrochromic switching performance. Ceram. Int. 2020, 46, 10578-10584. [CrossRef]

22. Kawashima, T.; Ezure, T.; Okada, K.; Matusi, H.; Goto, K.; Tanabe, N. FTO/ITO double layered transparent conductive oxide for dye-sensitized solar cells. J. Photochem. Photobiol. A Chem. 2004, 164, 199-202. [CrossRef]

23. Lee, K.; Kim, A.-Y.; Park, J.H.; Jung, H.-G.; Choi, W.; Lee, H.Y.; Lee, J.K. Effect of micro-patterned fluorine-doped tin oxide films on electrochromic properties of Prussian blue films. Appl. Surf. Sci. 2014, 313, 864-869. [CrossRef]

24. Koo, B.-R.; Oh, D.-H.; Riu, D.-H.; Ahn, H.-J. Improvement of Transparent conducting Performance on Oxygen-Activated FluorineDoped Tin Oxide Electrodes Formed by Horizontal Ultrasonic Spray Pyrolysis Deposition. ACS Appl. Mater. Interfaces 2017, 9 , 44584-44592. [CrossRef] [PubMed]

25. Chapron, D.; Girtan, M.; Le Pommelec, J.-Y.; Bouteville, A. Droplet dispersion calculations for ultrasonic spray pyrolysis depositions. J. Optoelectron. Adv. Mater. 2007, 9, 902-906.

26. Perednis, D.; Gauckler, L.J. Thin Film Deposition Using Spray Pyrolysis. J. Electroceram. 2005, 14, 103-111. [CrossRef]

27. Noor, N.; Parkin, I.P. Enhanced transparent-conducting fluorine-doped tin oxide films formed by aerosol-assisted chemical vapour deposition. J. Mater. Chem. C 2013, 1, 984-996. [CrossRef]

28. Wang, J.T.; Shi, X.L.; Zhong, X.H.; Wang, J.N.; Pyrah, L.; Sanderson, K.D.; Ramsey, P.M.; Hirata, M.; Tsuri, K. Morphology control of fluorine-doped tin oxide thin films for enhanced light trapping. Sol. Energy Mater. Sol. Cells 2015, 132, 578-588. [CrossRef]

29. Bae, J.-W.; Koo, B.-R.; An, H.-R.; Ahn, H.-J. Surface modification of fluorine-doped tin oxide films using electrochemical etching for dye-sensitized solar cells. Ceram. Int. 2015, 41, 14668-14673. [CrossRef]

30. Shin, D.-Y.; Koo, B.-R.; Ahn, H.-J. Lithium storage kinetics of highly conductive F-doped $\mathrm{SnO}_{2}$ interfacial layer on lithium manganese oxide surface. Appl. Surf. Sci. 2020, 499, 144057. [CrossRef]

31. Ravichandran, K.; Ananhi, R.; Sakthivel, B.; Swaminathan, K.; Ravikumar, P.; Begum, N.J.; Snega, S. Thickness Dependence of FTO Over-Layer on Properties of FTO/FZO Bilayer. Mater. Manuf. Process. 2013, 28, 1322-1326. [CrossRef]

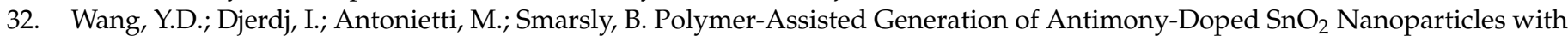
High Crystallinity for Application in Gas Sensors. Small 2008, 10, 1656-1660. [CrossRef]

33. Murakami, K.; Yagi, I.; Kaneko, S. Oriented Growth of Tin Oxide Thin Films on glass Substrates by Spray Pyrolysis of Organotin Compounds. J. Am. Ceram. Soc. 1996, 79, 2557-2562. [CrossRef]

34. Kumar, K.D.A.; Valanarasu, S.; Jeyadheepan, K.; Kim, H.-S.; Vikraman, D. Evaluation of the physical, optical, and electrical properties of $\mathrm{SnO}_{2}: \mathrm{F}$ thin films prepared by nebulized spray pyrolysis for optoelectronics. J. Mater. Sci. Mater. Electron. 2018, 29, 3648-3656. [CrossRef]

35. Yu, S.; Li, L.; Lyu, X.; Zhang, W. Preparation and investigation of nano-thick FTO/Ag/FTO multilayer transparent electrodes with high figure of merit. Sci. Rep. 2016, 6, 20399. [CrossRef] [PubMed]

36. Wang, M.; Liu, Q.; Dong, G.; He, Y.; Diao, X. Influence of thickness on the structure, electrical, optical and electrochromic properties of AZO thin films and their inorganic all solid-state devices. Electrochim. Acta 2017, 258, 1336-1347. [CrossRef] 
37. Koo, B.-R.; Kim, K.-H.; Ahn, H.-J. Novel tunneled phosphorus-doped $\mathrm{WO}_{3}$ films achieved using ignited red phosphorus for stable and fast switching electrochromic performances. Nanoscale 2019, 11, 3318-3325.

38. Wang, C.-K.; Lin, C.-K.; Wu, C.-L.; Brahma, S.; Wang, S.-C.; Huang, J.-L. Characterization of electrochromic tungsten oxide film from electrochemical anodized RF-sputtered tungsten films. Ceram. Int. 2013, 39, 4293-4298. [CrossRef]

39. Koo, B.-R.; Kim, K.-H.; Ahn, H.-J. Switching electrochromic performance improvement enabled by highly developed mesopores and oxygen vacancy defects of Fe-doped $\mathrm{WO}_{3}$ films. Appl. Surf. Sci. 2018, 453, 238-244. [CrossRef] 